\title{
Representation of Zero and Dummy Subject Pronouns within multi- strata dependency framework
}

\author{
Dina El Kassas \\ Faculty of languages and Translation \\ Minya University, Minya \\ Modyco Laboratory \\ Nanterre University, Paris \\ delkassas@gmail.com
}

\begin{abstract}
The objective of this paper is to discuss a formal representation of subject pronoun within a multi-strata dependency model. We propose criteria to describe consistently subject pronoun variations, naming subject pronouns that have no meaning and/or no morpho-phonological expression. We will present particular syntactic structures raised from a change of voice category; and will emphasize the problematic representation of Pro-Drop impersonal construction within the multi-strata framework.
\end{abstract}

\section{Introduction}

The present study aims to describe the typologically widespread pronoun dropping and the expletive pronoun subject phenomena. The representation is based on the core of the nature of linguistic sign as well as the main communicative function of the pronoun as a grammatical part of speech.

The term Pro-Drop describes a feature of some languages that does not require an obligatory overt actant to be present in the clause. Languages allowing Pro-Drop fall into three categories (Dryer, 2008): those allowing Pro-Drop only in particular context; those allowing Pro-Drop only in subject position; and those allowing both subject and direct object Pro-Drop.

The dropped subject pronoun is commonly identified by Universal Grammar as a null subject and is defined as a linguistic sign that has a meaning but doesn't have a phonetic realization. The result is an independent clause lacking an explicit subject. The verb agreement expresses person, number and/or gender with the referent. We will call it following Mean-
ing-Text Theory (MTT) terminology the zero pronoun. An MTT zero pronoun is exactly a linguistic sign that has a meaning of 'people' or 'element'.

Studies on expletive subject pronoun representation have focused on its semantic emptiness and its non-referential (non-endophoric) status. The construction including an expletive subject pronoun governed by finite verbal clause is commonly identified as impersonal construction. Again, following the terminology used in MTT, we will call it the dummy pronoun.

We propose a formal description of zero and dummy pronouns within the framework of MTT that offers a rigorous exhaustive coverage of linguistic sign and makes explicit its intersection with voice (Mel'čuk, 2006). As in many other dependency frameworks (XDG, FDG ...), MTT model posits multiple strata of representations related by explicit interfaces. The study refers primarily to examples from the Arabic.

The paper is structured as follows:

Section 2 presents: the linguistic sign as described within the MTT framework; a typology covering sentences featuring zero and dummy subjects; and a formal treatment of these constructions within the Meaning-Text dependency syntax framework.

In Section 3, we discuss the grammemes of the Arabic voices. The objective is to shed light on some issues concerning zero and dummy construction representations provoked by the deep-syntactic level.

Section 4 is dedicated to the conclusion and future work.

We take for granted the basic notions of the Meaning-Text dependency syntax (Mel'čuk, 1988), such that the representations are multistratal with intermediate interfaces. 
The sentence structure at the semantic level is a dependency network. Each node is labeled by a language-specific semantic unit which corresponds to one particular word-sense. The oriented arcs connect the head predicate to its arguments, or semantic actants. Arc labels are consecutively numbered. These numbers distinguish semantic relations of the argument-topredicate type. Roughly, the numbering follows the needs of semantic decomposition.

The sentence structures at deep and surface syntactic levels are dependency trees with lexemes being represented as nodes and syntactic relations as arcs. At the deep-syntactic level, the syntactic relations presenting actant relations are numbered by I, II, III, etc. and are assumed to be universal. At the surfacesyntactic level, the encoded syntactic relations are language-specific functions (e.g. subject, direct object, oblique-object etc.).

\section{Linguistic sign in MTT}

According to the traditional Saussurean definition, a linguistic sign combines a signifier (a sound image, i.e. signifiant) and a signified (a concept, i.e. signifié). So, if $\mathrm{x}$ is a sign, $\mathrm{x}$ should be a combination of a phonetic realization and a meaning.

To these two components of the linguistic sign entity, a set of properties is added to give necessary syntactic information that specifies the correct combination of the given sign with other.

In MTT, the lexeme assuming the surfacesyntactic subject function should be linked to nodes in both deep morpho-phonological and deep-syntactic levels and must have its own syntactics.

When the subjectal role is assumed by a pronoun, it should normally have an endophoric function, i.e. it should refer to another lexeme in the text. We have thus a first distinction: "endophoric $\sim$ non endophoric [subject pronoun]" (or a personal impersonal pronoun). Additionally, the subject pronoun may or may not have a morpho-phonological realization. Here comes the second distinction: "overt zero [subject pronoun]".

By subject pronoun, we refer only to the third personal pronouns such as English HE, SHE or THEY that assume a referential function but don't have a meaning in opposition with pronouns such as English I, WE or YOU that do have a meaning.
According to these two distinctions, we have four possible combinations in case of subject pronoun:

1) Subject pronoun having a phonetic realization and filling an endophoric function $\rightarrow$ [full pronoun]

It is off-topic to discuss here full pronoun. At any rate, subjects of type (1) are not relevant for our topic. The pronominalized and communicatively salient subject appears on the surface in Anti-Pro-Drop structures. The indefinite pronouns ON (French) and MAN (German) linked to the semantic collective/generic actant are considered as subject full pronouns.

2) Subject pronoun having no phonetic realization but filling an endophoric function $\rightarrow$ [zero pronoun]

By zero pronoun, we mean a pronoun that is morpho-phonetically empty. We are aware that the term in MTT terminology refers to zero meaning and not zero physical expression. Yet, we use it for lack of a better term. The subject pronoun appears in the SSyntS as a meaningful zero or empty lexeme and controls the agreement of the verb. Arabic has a wide range of sentences lacking an overt sentence element. For example, the copula KĀNA '(to) be' has a zero present indicative form and governs sentences traditionally called nominal sentences:
(1) $\emptyset_{\text {kāna 'alqalaqu mubarrarun }}$
V.is N.concern ADJ.justified
'Concern is justified'
vs. kāna 'alqalaqu mubarraran
V.was N.concern ADJ.justified
'Concern was justified'

Zero radicals are also frequent in Slavic, Romanian and Semitic languages. The zero sign lacks the signifier. The trace of the presence of a zero subject pronoun in the sentence is the feature of its syntactics that is copied on the verb via a rich agreement and is communicatively salient:

(2) Rus Stučat v dver' '[they] knock at door'

It Fumo '[he] smokes'

Sp Llaman a la puerta '[Someone] is

knocking the door'

Ar 'akalu ${ }_{\text {V.3.pl.masc }}$ '[they] ate'


apple'

In Arabic, the subject pronoun is not realized phonetically and the verb exhibits a full PNG agreement. The Arabic inflected verb agrees with its subject pronoun in person $(1,2$, 3 ), number (singular, dual, plural) and gender 
(masculine, feminine). This rich verb agreement allows the suppression, or more precisely the non-realization of the pronominal inaccentuated subject, avoiding thus a grammatical redundancy without giving rise to any ambiguity:

$$
\begin{aligned}
& \text { (3) 'akali } \overline{\boldsymbol{u}}_{\mathrm{V} \text {.eat.active.past.3.masc.pl }} \\
& \text { 'akalna } \boldsymbol{a}_{\mathrm{V} \text {.eat.active.past.3.fem.pl }} \\
& \text { 'ukil } \overline{\boldsymbol{u}}_{\mathrm{V} \text {.eat.passive.past.3.masc.pl }}
\end{aligned}
$$

The meaningful subject pronoun with zero form may be compatible with a specific individual who satisfies the description, giving so an existential reading, but it may also imply a generic universal reading. In both cases, the morpho-phonetically zero-subject pronoun denotes an endophoric relation with a full lexeme in the sentence or the text. This pronoun must be distinguished from the dummy-subject one commonly described as an impersonal construction (cf. figure 1).



Figure 1: zero-form meaningful subject pronoun

Zero subject sign has to be carefully distinguished from deleted subject. The syntactic operation of deletion or ellipsis consists in removing a sign from a representation, like when we answer a question; while zero sign lacks the overt signifier but is not omitted. There are different types of ellipsis but we are not interested here in the distinction between discourse ellipsis and Pro-Drop phenomenon. Let's just mention that an elided subject can be reconstituted in context, but a zero-form subject pronoun cannot. In the following example, the subject hathā is elided.
(4) - hal
hathā mumkinun?
interro. this
possible
'Is this possible?'
- nacam hathā mumkin dziddan
yes possible very
'Yes, it is very possible'.

Meteorological expressions present also a case of meaningful subject dropped pronoun. In sentences (5a) and (5b), the verb agreement presents a case of zero-form semantically full pronoun: the verbs are at the active.present.3.fem.sg inflectional forms and indirectly govern the pronoun $h \bar{a}_{3 \text {.fem.sg, }}$, referring to alsama $\bar{a}^{\prime}$ 'the sky' which is a feminine noun in Arabic.

$$
\begin{aligned}
& \text { (5) a. 'inna }=h \bar{a} \quad \text { tumtir }\left[\varnothing_{\mathrm{PRO}}\right] \\
& \text { Particule }=\mathrm{PRO}_{3 . \text { fem.sg }} \quad \mathrm{V}_{\text {act.pr.3.fem.sg }}[\mathrm{she}] \\
& \text { assert=she rains } \\
& \text { '[she] rains' } \\
& \text { b. } \operatorname{tar}^{c} a d u\left[\emptyset_{\mathrm{PRO}}\right] \quad \text { tabruqu }\left[\emptyset_{\mathrm{PRO}}\right] \\
& \mathrm{V}_{\text {act.pr.3.fem.sg [she] }} \mathrm{V}_{\text {act.pr.3.fem.sg [she] }} \\
& \text { thunders lightens } \\
& \text { '[she] thunders' | '[she] lightens' }
\end{aligned}
$$

It is also accurate to assign to meteorological verbs the noun alsama $\bar{a}^{\prime}$ as an explicit SSynt subject, thus the following sentences are correct: 'tumtir alsamā' $u$ ', 'tar'adu alsamā' $u$ ', etc. This assignation of meteorological verbs to the appropriate nature force is frequent in Arabic:

$\begin{array}{cc}\text { (6) a. tahubbu } & \text { alrijāhu } \\ \mathrm{V}_{\text {act.pr.3.fem.sg }} & \mathrm{N}_{\text {fem.Nom }} \\ \text { blows } & \text { the winds } \\ \text { 'It blows' } & \\ \text { b. jabzugi } u & \text { alfadzru } \\ \mathrm{V}_{\text {act.pr.3.masc.sg }} & \mathrm{N}_{\text {fem.Nom }} \\ \text { emerged } & \text { the dawn } \\ \text { 'It dawns' } & \end{array}$

The corresponding equivalent in Anti-ProDrop language like English is generally an impersonal construction with a semantically empty explicit subject pronoun.

3) Subject pronoun having phonetic realization but not filling an endophoric function $\rightarrow$ [dummy pronoun]

The subject is semantically empty and thus presents a dummy sign which is defined as a sign lacking the signified. The dummy subject occurs in impersonal constructions. Indeed, an impersonal construction is defined by the presence of an automatically generated subject pronoun that does not correspond to a deepsyntactic / semantic actant, which means that the pronominal subject is not assuming an endophoric function in the discourse. The term 'impersonal construction' is quite felicitous but it is so entrenched in the linguistic literature that it is impossible to spare. However, we find it more accurate to talk about a semantically empty non-endophoric subject pronoun and so, only $3^{\text {rd }}$ singular pronoun may be the subject of an impersonal construction, $1^{\text {st }}$ and $2^{\text {sd }}$ pronouns cannot be the subject of an impersonal construction as they have semantic referents. We have examples of dummy sign in 
Anti-Pro-Drop languages: IT (English), IL (French), etc.

(7) a. Fr. Il tonne = 'It thunders'.

b. Fr Il est arrivé 3 personnes $=$ 'It comes 3 persons'.

c. Fr Il a été détruit 3 camions = 'It was destroyed three trucks'.

In principle, the dummy construction can be used with all types of verbs (transitive, intransitive, pronominal) and combines with voice grammemes in the language. Figures (2) and (3) present semantic and syntactic patterns of impersonal constructions:

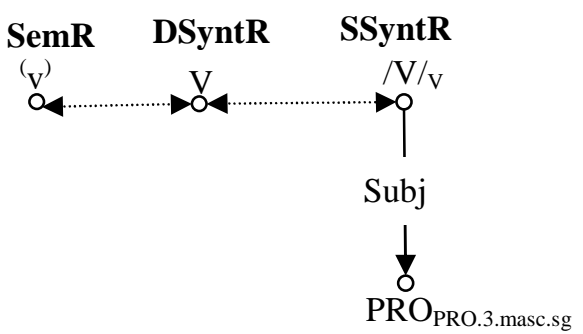

Figure 2: Impersonal construction (7a)

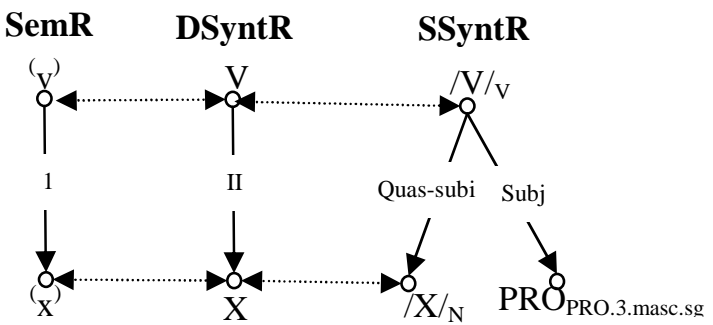

Figure 3: Impersonal construction (7b) and (7c)

4) Subject pronoun having no phonetic realization and not filling an endophoric function $\rightarrow$ [dummy zero pronoun]

The fourth case presents subjectless sentences including those lacking subjects even in the SSyntS. The pronoun represents a sign lacking both the signified and the signifier:

(8) It. Piove 'Rains' = 'It rains'

Serb. Grmi 'thunders' = 'It thunders'

Arabic has a particular zero-subject pronoun featuring an impersonal structure, as in the examples (9a) and (9b) featuring a subjective suppressive voice; the verbs are systematically in the SubjSupp.3.masc.sg inflectional form:
(9) a. murra
bi=hindin
$\mathrm{V}_{\text {SubjSup.3.masc.sg }} \quad \mathrm{PREP}=\mathrm{N}_{\mathrm{GEN}}$
passed by=Hind
'[Someone] passed by=Hind'

$$
\begin{array}{ll}
\text { b. nīma } & f i \quad \text { aldāri } \\
\mathrm{V}_{\text {SubjSupp.3.masc.sg }} & \text { PREP } \mathrm{N}_{\text {GEN }} \\
\text { slept } & \text { in the.house } \\
\text { '[Someone] slept in the house' }
\end{array}
$$

We will discuss thoroughly the SubjSupp grammeme in section 3. Let's say here that, on the one hand, the subject pronoun has no physical expression and thus presents a zero pronoun. On the other hand, it will not be accurate to describe it as a dummy zero pronoun because it is not semantically empty: even if the zero-subject pronouns in examples (9a) and (9b) are not linked to specific entities, the sentences still have an existential reading: 'one or few persons passed by Hind', 'one or few persons slept in the house'. The semantic actant in both cases must be a human agent: the subject pronoun of a verb in the subjective suppressive voice could not correspond to a non-human agent. Thus, the sentences marra alkilābu $b i=$ hindin 'the dogs passed by Hind' could not be transformed to the subjective suppressive. We would rather refer to this structure as an INDEFINITE PERSONAL like in the Russian tradition, or the pronoun 'ON' in French.

As we see, the study of zero and dummy subject pronouns is intrinsically related to voice grammemes that it's why the next section will be dedicated to the formal representation of voice grammemes in Arabic.

\section{Formal Representation of Voice Category in MTT}

In the MTT framework, a diathesis of a wordform is defined as the correspondence between its Semantic and Deep-Syntactic Actants $(\operatorname{SemA} \Leftrightarrow \mathrm{DSyntA})^{1}$; voice is a semantic inflectional category whose grammemes specify modifications of the basic diathesis of a lexical unit $\mathrm{L}$ without affecting the propositional meaning of $\mathrm{L}^{2}$. The basic diathesis of $\mathrm{L}$ is its lexicographic diathesis. Voices help to construct different messages about the same situation.

As we said above, the semantic actant corresponds to the argument of the predicate and is identified by a distinctive asemantic number. A DSynt A of a lexical unit $L$ is another lexical unit depending syntactically on L and corresponding to a SemA of L or to a SurfaceSyntactic Actant [SSyntA] of $\mathrm{L}^{3}$. An important

\footnotetext{
${ }^{1}$ Mel'čuk, 2006, p. 187.

${ }^{2}$ Idem, p. 191.

${ }^{3}$ Idem, p. 184.
} 
feature of DSyntAs is their intermediate character as an interface between the SemAs and the SSyntAs of a lexical unit: they are determined either semantically or surfacesyntactically. The dummy subject, whether with expletive or no physical expression, does not appear in the DSyntS.

DSyntA are identified by meaningful Roman numbers and ordered following the decreasing obliqueness. Each number corresponds to a family of surface-syntactic constructions brought together because of their similarity. Thus, DSyntA I stands for the syntactic constructions that express the subjectal SSynt-relation; DSyntA II represents, among others, the DirO, the Indirect or Oblique object, and the Agentive complement with the passive form of a transitive verb; DSyntA from III to VI represent more oblique objects/complements.

The diathesis of $\mathrm{L}$ can be modified by one of the following three operations: PERMUTATION of the DSyntAs of $L$ with respect to the corresponding SemAs, SUPPRESSION of DSyntAs of L (which means that the SemA involved cannot be manifested syntactically as a direct syntactic dependent of L. This means blocking the slot of this DSyntA), REFERENTIAL IDENTIFICATION of two SemAs, with obligatory suppression of at least one DSyntA.

There are four possible main voices: active, passive, suppressive and reflexive. The passive voice consists of assigning another DSynt-role (II or III) to the expression that fills the DSyntrole I in the active voice. There are five possible passive voices:

- Full, if both DSyntAs of L are affected (I $\Rightarrow$ II and simultaneously II $\Rightarrow$ I).

- Partial, if only one of the DSyntAs of L is affected (I $\Rightarrow$ III, while II remains in place and nothing becomes I).

- Promotional, if the passive promotes the DSyntA II to I and demotes the DSyntA I.

- Demotional, if the passive demotes the DSyntA, without promoting anything.

- Agentless, if the passive does not allow for an Agentive Complement.

According to this formalism, Arabic has the following six voice grammemes:

\section{1) Active voice [Act.]}

It is the basic diathesis: the DSyntA I corresponding to the primary semantic argument is linked to the SSynt subject $\left[{ }^{\prime}{ }_{1}{ }_{1}, \mathrm{X}_{\mathrm{I}}, / \mathrm{x} /\right.$ subj $]$ :

\begin{tabular}{|l|l|}
\hline $\mathrm{X}$ & $\mathrm{Y}$ \\
\hline $\mathrm{I}$ & $\mathrm{II}$ \\
\hline Subject & Object \\
\hline
\end{tabular}

The Zero-Subject pronoun in the active voice has a full meaning, a syntactic presence but no physical expression [' $\left.{ }^{\prime}{ }_{1}, \mathrm{X}_{\mathrm{I}}, / Ø /_{\text {subj-pro }}\right]$. The verb may be transitive (10a) or intransitive (10b), regardless of the verb tense:

$$
\begin{gathered}
\text { (10) a. qālat } \emptyset_{\text {pro.3.fem.sg }} \text { alhaqa } \\
\mathbf{V}_{\text {act.past.3.fem.sg }} \mathrm{N}_{\text {def.ACC }} \\
\text { said [she] } \quad \text { the truth } \\
\text { '[She] said the truth' } \\
\text { b. janaamuun } \emptyset_{\text {pro.3.mas.pl }} \\
\mathbf{V}_{\text {act.pres.3.masc.pl }} \\
\text { are.sleeping [they] } \\
\text { '[They] are sleeping' }
\end{gathered}
$$

It will not be accurate to consider the above sentences as elliptical constructions. The omission is not intentional but grammatically required: the pronoun filling the subject function does not have a morpho-phonetic expression. We prefer distinguishing between the grammatical obligatory omission and the discursive or stylistic omission even if the latter one is occasionally obligatory also.

We should also differentiate the zero subject pronoun from the completive clause that may fill the subject function as in the following example:

\section{(11) balagha $=n \bar{\imath}[\text { anna }=k a \text { satarhalu }]_{\text {subjClause }}$ $\mathrm{V}_{\text {act.pr.3.masc.sg }}=\mathrm{PRO}_{1 . \mathrm{pl}}[\mathrm{CONJ}=\mathrm{PRO} \mathrm{V}]_{\text {subj }}$ was.informed $=m e \quad$ [that=you will.leave] 'I was informed that you will leave'.}

\section{A Demotional Active voice [DemAct.]}

The detransitivization of some verbs may feature an impersonal construction: the subject is a dummy zero subject pronoun $\left(\varnothing_{\text {3.MASC.SG }}^{\varnothing}\right.$, the SemA $1[\mathrm{X}]$ is demoted to DSyntA II rank, the SemA 2 is omitted and the DSyntA III [Y] keeps its rank:

\begin{tabular}{|l|l|}
\hline X & Y \\
\hline II & III \\
\hline OblO & OblO \\
\hline
\end{tabular}

Let's take the example of the trivalent verb KAFAA meaning 'suffice' ( $\mathrm{X}$ suffices as $\mathrm{Y}$ for $\mathrm{Z):}$

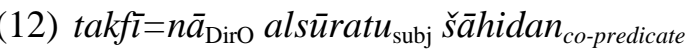 $\mathrm{V}=\mathrm{PRO} \quad \mathrm{N}_{\text {def.NOM }} \quad \mathrm{N}_{\text {indef.ACC }}$ suffice $=$ us the.picture a.witness 'The picture suffices for us as a witness' 
The verb is in the demotional active present 3 feminine singular form as in agreement with the singular feminine noun alsüratu filling the subject function. Its actants are distributed as follow:

\begin{tabular}{|l|l|l|}
\hline X & Y & Z \\
\hline I & II & III \\
\hline Subj & DirO & CoPred \\
\hline alsūratu & $n \bar{a}$ & šăhidan \\
\hline
\end{tabular}

The co-predicate may be omitted without affecting the sentence's grammaticality: 'takfi=na alsūratu'. The direct object may also be omitted: 'takfi alsüratu', meaning 'the picture suffices' or 'the picture is enough'. The DSyntA III could be realized as an obliqueobject: 'takfi alsūratu $k a_{\mathrm{PREP}}=\check{s} \bar{a} h i d i n_{\mathrm{GEN}}$ '.

The verb may also have a particular government pattern with a demoted DSyntA I as in the following sentence:

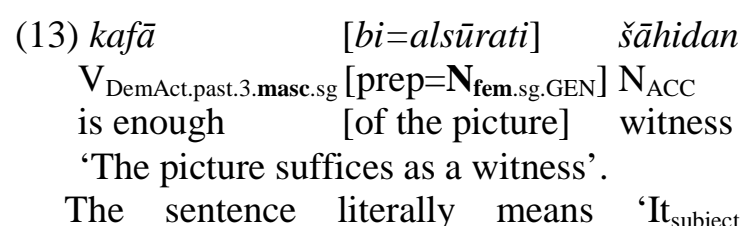
makes_sufficient witness ${ }_{\text {CoPred }}$ with the pic-

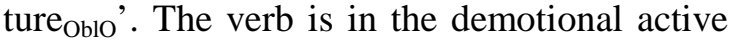
past 3.masculine.singular form. It will not be inaccurate to use the verb in the present form, yet we don't notice a frequent use of it: 'jakfi bi=alsūrati šâhidan'. The valency of kafā $\bar{a}_{\text {act.prlpast.3.masc.sg }}$ is $\left(\emptyset_{\text {subj, }}\right.$ OblO, CoPred $)$.

We can't follow the Arabic traditional grammar and analyze the prepositional phrase [bi=alsūrati] as a subject. We have here a demotional transformation of the DSyntA I from SSynt Subject rank to SSynt Oblique Object rank, the result is an impersonal construction with a subject pronoun featuring no meaning and no morpho-phonetic realization. The verb is systematically in the DemAct.3.MASC.SG inflectional form.

Some verbs govern by default this exceptional construction. In the following sentences the verb is systematically in the DemAct.3.MASC.SG whether the verb is in the past (14a) or the present (14b) form even if the lexemes expressing the SemA I are feminine nouns. These examples express the exclusion: the verb preceded by a negative particle governs an exclusive construction composed of the exclusive particle 'illa followed by a noun re- ferring to the SemA I of the verb in the affirmative form.

$$
\begin{aligned}
& \text { (14) a. } m \bar{a} \text { fāza 'illa 'anti } \\
& \mathrm{Pa} \mathrm{V}_{\text {DemAct.past.3.masc.sg }} \mathrm{Pa} \quad \mathrm{PRO}_{\text {2.fem.sg }} \\
& \text { neg won except you } \\
& \text { 'Only you have won' }
\end{aligned}
$$

The pronoun ['illa 'anti $i_{2 . f e m . s g}$ ] or the noun ['illa 'alfatajātu ${ }_{3 . f e m . p l}$ ] could not be considered as the subject of the head verbs for several reasons:

First, the verbs do not agree in gender with these elements.

Second, the verbs are in the negative form or these lexical elements correspond to the SemA I of the verbs in the affirmative form, as it shows the translation.

Third, as we said above, the subject pronoun has no physical expression in Arabic and so the pronoun 'anti in (14a) cannot fulfill the subject function. This pronoun will disappear for example in the affirmative non-exclusive construction: $f u z t i_{\text {Act.past.2.fem.sg }}$ 'you won'. By analogy, the noun 'alfatajātu in (14b) is not the subject. The sentences may be literally translated by: 'It won not except you' and 'It enters not the site except the girls'.

For these reasons, in my opinion, it will be pertinent to distinguish between an active and a demotional active voice.

\section{2) Full Promotional Passive voice}

In Arabic, as in Semitic languages, the passive voice is originally used only when the agent could not be expressed because it is unknown or the speaker does not want to name it. Therefore, the general rule is that the verb in the passive voice does not govern an agentive complement corresponding to the SemA I. However, even if the full passive voice is not frequent in Arabic, there are a number of prepositions and complex prepositions that are believed to be the equivalent of English agentive by. The SemA 1 is demoted to the DSyntA II rank, and conversely, DSyntA II is promoted:

\begin{tabular}{|l|l|}
\hline $\mathrm{X}$ & $\mathrm{Y}$ \\
\hline $\mathrm{II}$ & $\mathrm{I}$ \\
\hline $\mathrm{AgCo}$ & Subject \\
\hline
\end{tabular}


The most common prepositions and complex prepositions introducing an agentive complement (AgCo) are: /bi/, /li//min/ / $\mathrm{c}$ abr/ 'by'; /bi-sababi/ 'because of'; /min dzānibi/ 'from the side of'; /'alā jadi/'ajdi/ 'at the hand/s of'; /min qibali//min khilāli/ 'on the part of'; /biwāsitala/; /'an tarīqi/ 'by means of'. The agentive complement may denote a human agent (15a) and (15b) or an entity expressing the way or the instrument (15c) and (15d):

(15) a. kutibat alriwāyatu biwāsitati zajdin was.written the.novel by Zayd 'The novel was written by Zayd'.

b. futiḥat alrisālatu 'an tarīqi almustaqbili was.opened the.message by the.receiver

'The message was opened by the receiver'.
c. futiha albarīdu ${ }^{c}$ an tarīqi mawqi $i^{c}$ was.opened the.mail by my.site
'The mail was opened by my site'.
d. munic a albaladu' ${ }^{c}$ abra al'istiftā'i was.prevented the.country by the.referendum

'The country was prevented by the referendum'.

The full passive transformation is strongly due to the impact of translation from European languages in contemporary practice, particularly in journalism and IT fields. In the active voice, the agentive complement is promoted to the subject rank. Examples (16) present the active transformation of the sentences in (15): the agent regains its position as a subject in the nominative form followed by the direct object in the accusative form (ended by the vowel $/ \mathrm{a} /)$.

(16) a. kataba zajdun subj $_{\text {alriwāyata }}$

b. fataha almustaqbilu subj $_{\text {alrisālata }}$

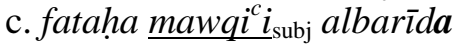

d. mana ${ }^{c}$ a $\underline{\text { al'istiftát' }}_{\text {subj }}$ albalada

\section{3) Agentless passive voice [AgPass]}

It is the most frequent passive in Arabic. The passivization of a bivalent verb consists of the suppression of the DSyntA I corresponding to the subject in the basis diathesis and the promotion of the DSyntA II. The agentless passive voice is intrinsically related to the detransitivization process. In the remainder of the sub-section, we will present three specific cases: first the passivization of verbs governing 'an/'anna 'that'-construction, the decreasing of the valence of bivalent verbs (intransitivization), then the decreasing of the valence of trivalent verbs governing a clausal object.
1) Verbs governing 'an/anna-constructions

The government pattern of some verbs categories, mainly verbs of speech includes three actants: a subject, an 'an/annaconstruction as a direct object, and according to the verb, an indirect object. With the agentless passivization process, the direct object completive clause is promoted to the subject rank:

\begin{tabular}{|l|l|}
\hline $\mathrm{X}$ & $\mathrm{Y}$ \\
\hline- & $\mathrm{I}$ \\
\hline- & Subject'an/anna-construction \\
\hline
\end{tabular}

No changes occur in the clause and the verb is systematically in the 3.masc.sg inflectional form (17a). We notice that some verbs are more frequently used in the passive form rather than the active on (17b). The most common equivalent in this case is the impersonal construction $\{\mathrm{IT}+$ to be $+\mathrm{ADJ}\}$. Yet, the Arabic construction is not an impersonal one: the head verb governs systematically a completive clause as subject.
(17) a. luhitha
$\mathrm{V}_{\text {AgPass.past.3.masc.sg }}[\mathrm{CONJ} . . .]_{\text {subj_Clause }}$
noticed [that...]
'It was noticed that...'.
b. justahsanu ['an tahdira $]_{\text {subj_Clause }}$
$\mathrm{V}_{\text {AgPass.past.3.masc.sg }}[\mathrm{CONJ} \text {... }]_{\text {subj_Clause }}$
is.better [that you.come]
'It would be better if you come'.

2) Intransitivization

When a bivalent verb undergoes agentless passivization, the direct object is promoted to the subject rank and the SemA 1 is not expressed:

\begin{tabular}{|l|l|}
\hline$X$ & $Y$ \\
\hline- & I \\
\hline- & Subject \\
\hline
\end{tabular}

The lexeme filling subject SSynt Relation has generally a vague or a general meaning like [en. MATTER], [fr. AFFAIRE] and [ar. 'AMR] (18 a-b). We note that the verb agrees in gender with the lexical subject.
(18) a. qudija ['al'amru $]_{\text {subj }}$
$\mathrm{V}_{\text {AgPass.past.3.masc.sg }} \mathrm{N}_{\text {def.masc.sg.NOM }}$
was.settled the.matter
'The matter was settled'
b. nuthirat $\quad[\text { al=mas'alatu }]_{\text {subj }}$
$\mathrm{V}_{\text {AgPass.past.3.fem.sg }} \mathrm{N}_{\text {def.fem.sg.NOM }}$
was.reviewed the issue
'The issue was reviewed' 
The SSynt subject role may be filled by a non dummy zero morpho-phonological subject pronoun: a pronoun, as we said above, having a full meaning, a syntactic presence but no physical expression. In the following examples, the non dummy zero subject pronoun is the $3^{\text {rd }}$ masculine plural personal pronoun in (19a), the $1^{\text {st }}$ singular personal pronoun in (19b) and the $2^{\text {sd }}$ feminine singular pronoun in (19c). The subject identification was allowed by the verb agreement. So, even if the subject pronoun is deprived of a physical expression, it has a full meaning and a syntactic presence.
(19) a. qutilū $\emptyset_{\text {subj-pro }} \operatorname{djamīa~} a n$
$\mathrm{V}_{\text {AgPass.pr.3.masc.pl }}$
$\mathrm{N}$
have been killed
all
'They all have been killed'.
b. 'ukaddabu $\emptyset_{\text {subj-pro }}$ dā'iman
$\mathrm{V}_{\text {Ag.Pass.pr.1.sg }}$ ADV
am accused of lying always
'I am always accused of lying'.
c. bulligti $\emptyset_{\text {subj-pr } \quad b i=n a d j a ̄ h u=k i}$
$\mathrm{V}_{\text {AgPass.pr.2.fem.sg }} \quad \mathrm{PREP}=$ masdar $=\mathrm{PRO}$
was informed by=success=yours
'You was informed of you success'.

3) Decreasing the valence of trivalent verbs

The passivization of trivalent verbs governing a clausal object, e.g. 'arā ( $\left.\mathrm{X}_{\mathrm{I}}, \mathrm{Y}_{\mathrm{II}}, \mathrm{Z}_{\mathrm{III}}\right){ }^{\text {' } \mathrm{X}}$ show to $\mathrm{Y}$ that $\mathrm{Z}$ ', consists of the suppression of DSyntA I, the promotion of the DSyntA III to DSyntA I rank while DSyntA II keeps its rank:

\begin{tabular}{|l|l|l|}
\hline$X$ & $Y$ & $Z$ \\
\hline- & II & I \\
\hline- & Obj.Clause & Subject \\
\hline
\end{tabular}

In the example (20), the verb is in the $2^{\text {sd }}$ singular form. The SSynt subject role is filled by a non dummy zero morpho-phonological subject pronoun. There is a particular communicational issue with the verb 'ara $\bar{a}$ in this context: the sentence literally means 'You are shown what happened', however its accurate English equivalent is 'I wonder what happened'. This discernible communicational change is due to the agentless passivization transformation. In the Arabic sentence, even if the subject is a non dummy pronoun, it is not individuated. The subject pronoun does not also support a general reading. The example (20) presents so a syntactic constraint structure. It closest equivalent in English is the sentence 'I wonder...'
(20) $\operatorname{turāa} \emptyset_{\text {pro }} \quad[m \bar{a} z \bar{a} \text { hadath }]_{\text {Obj_clause }}$
$\mathrm{V}_{\text {AgPass.pr.2.s.g }}\left[\right.$ interro. $\mathrm{V}_{\text {act.pr.3.masc.sg] }}$
is.shown [what happened]
'You are shown what happened'.

\section{4) Partial Agentless passive voice [PaAg- Pass]}

The partial agentless passivization process concerns verbs governing a completive clause or a free direct/indirect speech. It denotes a detransivization process: the DSyntA I is omitted, the DSyntA II corresponding to the completive clause and the DSyntA III, in case of trivalent verb, are respectively promoted.

\begin{tabular}{|l|l|l|}
\hline$X$ & $Y$ & $Z$ \\
\hline- & I & II \\
\hline- & Subj.Clause & ObjCo \\
\hline
\end{tabular}

The Examples (21) present the passivization of trivalent verb $q \bar{a} l a\left(\mathrm{X}_{\mathrm{I}}, \mathrm{Y}_{\mathrm{II}}, \mathrm{Z}_{\mathrm{III}}\right){ }^{\text {( } \mathrm{X} \text { say }}$ to $\mathrm{Y}$ that $\mathrm{Z}^{\prime}(21 \mathrm{a})$ and bivalent juntazaru $\left(\mathrm{X}_{\mathrm{I}}\right.$, $\left.\mathrm{Z}_{\mathrm{II}}\right)\left(\mathrm{X}\right.$ expecting that $\mathrm{Y}^{\prime}(21 \mathrm{~b})$. The verb agrees with the subject clause and is systematically in the $3^{\text {rd }}$ masculine singular inflectional form. The sentences do not present so an impersonal construction even if the English equivalent is.
(21) a. qūla
$[l a=h u]_{\mathrm{ObjCo}} \quad[\text { 'irhal }]_{\text {subj }}$
$\mathrm{V}_{\text {PaAgPass.3.masc.sg }}[\mathrm{PREP}=\mathrm{PRO}][]_{\text {clause }}$
was.said [to=him] [go]
'It was said to him: go'.
b. juntazaru ['an juthmira 'amalu=nā $]_{\mathrm{subj}}$
$\mathrm{V}_{\text {PaAgPass.3.masc.sg }}[]_{\text {clause }}$
is expected [that get fruitful our hope]
'It is expected that hope get fruitful re- sults'.

\section{5) Full suppression passive voice [FullSup- Pass]}

A distinctive feature of the MTT approach lies in the definition of voice based on a deep syntactic level as an intermediate. Any expression that syntactically depends on L and manifests a SemA of L is a DSyntA of L. Yet, a displacement process can take place: L may govern a DSyntA not corresponding to one of its SemAs. According to MTT: "An added displaced DSyntA is by definition unrelated to any of L's SemAs and therefore cannot modify the diathesis of $L^{\prime \prime}$.

Arabic full suppressive passivization process consists of the raising of an adjunct to the subject rank; the adjunct denotes the nomina-

\footnotetext{
${ }^{4}$ Mel'čuk, 2006, p. 192.
} 
tive case mark and triggers verb agreement (only for gender, as it is usual in VSO order). Both DSyntA I and II are suppressed and the DSynt A III is promoted: [DSyntA III, CircCo, Accusatif] $\Rightarrow$ [DSyntA I, Subject, Nominative].

\begin{tabular}{|l|l|l|}
\hline$X$ & $Y$ & $Z$ \\
\hline- & - & I \\
\hline- & - & Subject \\
\hline
\end{tabular}

In the examples (22), the DSyntAs III corresponding respectively to the SSynt circumstantial of time, place and manner are promoted to the SSynt subject rank by a full suppressive passivization process. The lexemes laylatun, almadinatu and farahun cannot be analyzed as direct objects because they denote the nominative case mark /u/:

$$
\begin{aligned}
& \text { (22) Time suhirat laylatun mumticatun } \\
& \mathrm{V}_{\text {pass .3.fem.sg }} \mathrm{N}_{\text {fem.NOM }} \mathrm{ADJ}_{\mathrm{NOM}} \\
& \text { was.stayed night funny } \\
& \text { 'The night was stayed funnily' } \\
& \begin{array}{ll}
\text { place qudijat } & \text { almadinatu } \\
\mathrm{V}_{\text {pass.3. }} \text { fem.so } &
\end{array} \\
& \text { was. spent [time] [in] the city } \\
& \text { 'The city was spent time in'. } \\
& \begin{array}{ccc}
\text { manner furiha } & \text { farahun } & \text { kabīrun } \\
\mathrm{V}_{\text {pass.3.masc.sg }} & \mathrm{N}_{\text {masc.Nom }} & \mathrm{ADJ} \\
\text { was.rejoiced joy } & \text { great } \\
\text { 'A great joy happened' } &
\end{array}
\end{aligned}
$$

An individuated Agent generally controls the action. Yet, this is not an unrestricted rule. In the following example, the agent is a dog. The meaning of the verb nubiha 'bark' disallows the individualization of the agent:

$$
\begin{aligned}
& \text { (23) manner } n \text { nubiha } \text { nibāḥun shadīdun } \\
& \mathrm{V}_{\text {pass.3.masc.sg }} \mathrm{N}_{\text {masc.Nom }} \mathrm{ADJ} \\
& \text { was barked barking intensive } \\
& \text { 'It was barked intensively' }
\end{aligned}
$$

The following figure presents the respective Semantic, DSynt and SSynt representations of the example (23). We note that the subject function is not filled by a semantic actant of the verb, and that the agent is not human.

\footnotetext{
${ }^{5}$ In these examples, the abbreviation 'pass' refers to the full suppressive passive grammeme. We ought to this abbreviation for space reason, but in example (24), we will use the abbreviation 'FullSuppPass'.
}

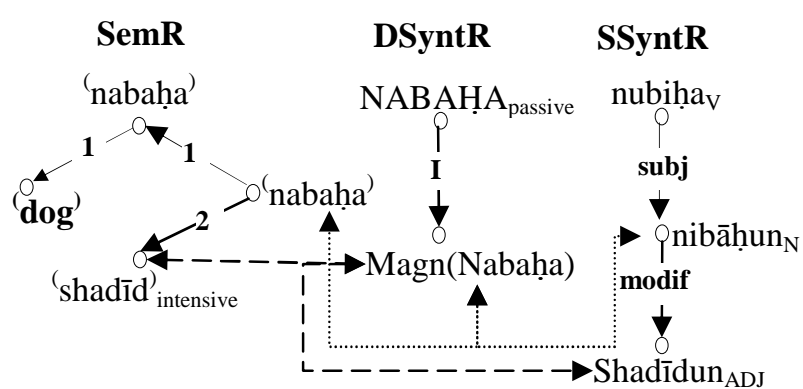

Figure 4: Full suppressive passivization process and non individuated agent

A "circumstantial aspect" may also be promoted to the subject rank. The "circumstantial aspect" or the "accusative of relation" is an indefinite singular noun corresponding to the SemA I of the verb (El Kassas, 2005). A synecdochic relation exists between the subject and the circumstantial aspect. The full suppressive passivization process consists of the suppression of the subject and the promotion of the circumstantial aspect to fill this function. In the following example, it exists a synecdochic relation between the lexeme /alkūbu/ 'the glass' and the lexeme /mā'an/ 'water'. The first one is the subject of the verb /fāda/ 'overflow' at the active voice, while the second one is promoted to the subject rank at the full suppressive passive voice.

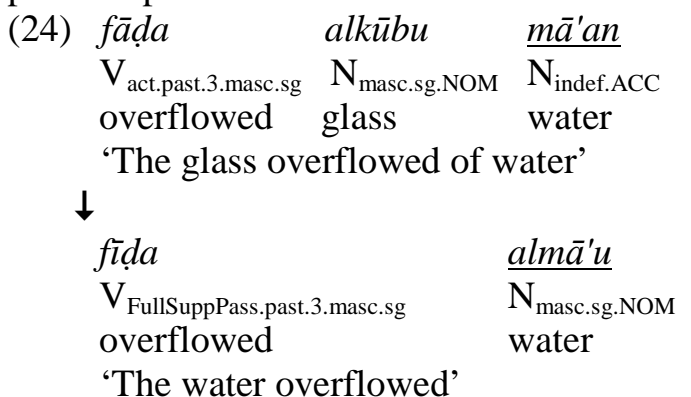

In brief, the verb in the full suppressive passive voice governs systematically a lexeme as a subject. We don't think that a pronoun could fill the subject function of the full suppressive passive voice.

\section{6) Subject suppressive voice (SubjSupp)}

This voice is commonly called impersonal passive. Like Slavic and some Romance languages, Arabic has no physical expression of impersonal pronoun. This analysis follows Teeple (2008), Saad 1982, Mohammad (1999), Fassi Fehri (1982), and Fischer (2002), but contrarily to them, we will not use the term impersonal passive that we find inaccurate. We will use rather the term subject suppressive voice. This voice occurs with indirect transitive verb: V (subject, oblique object). The DSyntA 
I is suppressed while the DSyntA II keeps its SSynt oblique rank. The SSynt subject role is fulfilled by a linguistic sign having no meaning and a zero phonetic realization. The head verb is only in the $3^{\text {rd }}$ masculine singular form.

\begin{tabular}{|l|l|}
\hline $\mathrm{X}$ & $\mathrm{Y}$ \\
\hline- & II \\
\hline- & OblO \\
\hline
\end{tabular}

We will content ourselves by mentioning that verbs accepting the subject suppressed voice may express, among others, a general or psychological situation (25a), a physiological (25b-c) state, or an action verb (25d). The $\mathrm{OblO}$ in all cases expresses the experiencer. We will not go any further in the semantic classification which will need more details.

$$
\begin{aligned}
& \text { (25) a. 'u'tunija } \quad[b i=h \bar{a}]_{\text {Oblo }} \\
& \mathrm{V}_{\text {SubjSupp.3.masc.sg }}\left[\mathrm{PREP}=\mathrm{PRO}_{\text {fem.sg }}\right]_{\text {oblO }} \\
& \text { was.taken.care [of=him] } \\
& \text { 'It was taken care of her' } \\
& \text { b. 'ugmija ['alaj=hi }]_{\mathrm{OblO}} \\
& \mathrm{V}_{\text {SubjSupp.3.masc.sg }}\left[\mathrm{PREP}=\mathrm{PRO}_{\text {masc.sg }}\right]_{\text {Oblo }} \\
& \text { was.fainted [on=him] } \\
& \text { 'He fainted' } \\
& \text { c. gurrira } \quad[\text { bi }=\text { him }]_{\mathrm{OblO}} \\
& \left.\mathrm{V}_{\text {SubjSupp.3.masc.sg }} \text { [PREP=PRO }{ }_{\text {masc.pl }}\right] \\
& \text { deceived } \quad[\mathrm{of}=\text { them }]_{\text {oblo }} \\
& \text { 'They was deceived' } \\
& \text { d. Ji'́a [bi=hindin }]_{\text {OblO }} \\
& \mathrm{V}_{\text {SubjSupp.3.masc.sg }}\left[\mathrm{PREP}=\mathrm{N}_{\text {fem.sg.GEN }}\right] \\
& \text { come [with-Hind] }]_{\text {oblo }}
\end{aligned}
$$

The oblique object may also express an action and be expressed by a masdiar:

$$
\begin{aligned}
& \text { (26) sumiha } \quad[\text { bi=alkhurūdzi }]_{\mathrm{OblO}} \\
& \mathrm{V}_{\text {SubjSupp }} \quad\left[\mathrm{PREP}=\mathrm{N}_{\text {masdar }}\right]_{\text {OblO }} \\
& \text { was allowed [to leave] } \\
& \text { 'It was allowed to leave' }
\end{aligned}
$$

The subject suppressive process can lower the SSynt rank of the DirO in a detransitivization process, no internal argument is promoted to the subject rank. For example, in (27) below, the lexeme almas'alata 'the issue' fills the direct object function in the active voice and denotes the accusative case mark /a/. In the passive voice, the lexeme is promoted to the subject rank, takes the nominative case mark / $\mathrm{u} /$ and governs the head verb agreement; while with the subject suppressive transformation, it is demoted to the oblique object rank and takes the genitive case mark /i/. The verb in this case is in the 3.masc.sg form and the subject is systematically a dummy zero pronoun. $\begin{array}{lc}\text { (27) } \text { natara } & {[\mathrm{X}]_{\text {subj }}[\text { almas'alata }]_{\text {DirO }}} \\ \mathrm{V}_{\text {act.pr.3.masc.sg }} & {\left[\mathrm{N}_{\text {deff.em.sg.ACC }}\right]} \\ \text { reviewed } & {[\mathrm{X}]_{\text {subj }}[\text { the issue }]_{\text {DirO.ACC }}}\end{array}$ ' $\mathrm{X}$ reviewed the issue'

$\begin{array}{ll}\text { nuthirat } & {\left[\text { almas'alatu }_{\text {subj }}\right.} \\ \mathrm{V}_{\text {pass.pr.3.fem.sg }} & {\left[\mathrm{N}_{\text {def.fem.sg.Nom }}\right]}\end{array}$

was.reviewed [the issue $]_{\text {subj.NOM }}$

'The issue was reviewed'

$\begin{array}{ll}\text { nuthira } & {[\text { fi almas'alati }]_{\text {OblO }}} \\ \mathrm{V}_{\text {SuppPass.pr.3.masc.sg }} & {\left[\text { PREP N } \mathrm{N}_{\text {def.fem.sg.GEN }}\right]} \\ \text { was.reviewed } & \text { [in the issue }]_{\text {Oblo.GEN }}\end{array}$

'It was reviewed in the issue'

In the traditional Arabic grammar, the prepositional constituent is analyzed as the subject. In my opinion, this analysis is totally inaccurate.

In case of intransitive or monovalent verb, the subject suppressive transformation consists of the omission of all verb' actants. In the following examples, the verbs govern only a circumstantial of place or time. Again the subject is a dummy zero pronoun and the verb systematically in the 3.masc.sg inflectional form:

$$
\begin{aligned}
& \text { (28) } \left.{ }_{\text {place }} \text { thuhiba ['ilā manzilu }=k a\right]_{\text {Circ }} \\
& \text { was.gone [to house=your }]_{\text {Circ }} \\
& \text { 'It was gone to your house'. } \\
& \begin{array}{ll}
\text { place } d z \text { ulisa } & {[f \overline{\text { algurfa }}]_{\text {Circ }}} \\
\text { was.sat } & {[\text { in the.room }]_{\text {Circ }}}
\end{array} \\
& \text { 'It was sat in the room'. } \\
& \text { time sufira [jawmu alsabti }]_{\text {Circ }} \\
& \text { was.traveled [day Saturday }]_{\text {Circ }} \\
& \text { 'It was traveled on Saturday' }
\end{aligned}
$$

As in a pro-drop language, impersonalization in Arabic means that the subject pronoun has no meaning and zero physical expression, which means that the subject function is fulfilled semantically, syntactically and morphologically by an empty actant. The analysis is rigorous yet the introduction of an empty element in this way jeopardizes its acceptability. The only justification of the presence of an empty subject in the sentence is to copy verb agreement. The following figure presents the representations of the sentence dzulisa [ $f i$ alghurfa] 'It was sat in the room'. As we see, the subject does exist syntactically while it has no deep-syntactic or morphological existence. 


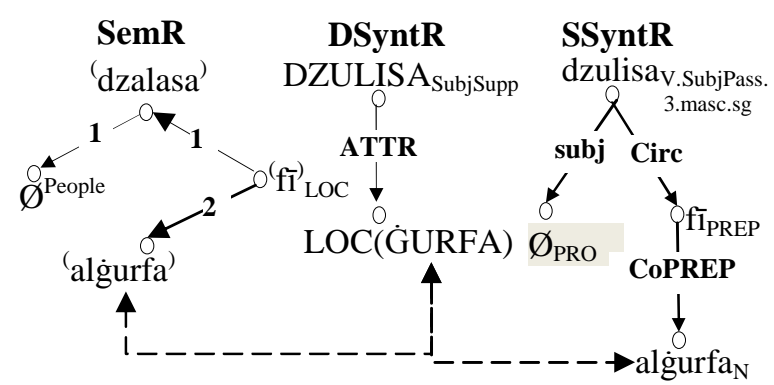

Figure 5: The subject suppressive voice

Describing the above sentence as an impersonal construction will not be accurate considering that there is no occurrence of a physical non endophoric pronoun like English IT; but it will be accurate if we consider that the first syntactic actant of the verb in the passive voice has no meaning: the primary semantic agent is not identified even if it is not empty and implies an individuated agent. The construction may have an existential reading: '[a specific person] stays in the room'.

\section{Conclusion}

In the present paper, we represented four categories of subject pronouns based on its endophoric function and phonetic realization. We described syntactic representation of unfamiliar structures where the subject pronoun exists only surface-syntactically. A particular attention was given to impersonal constructions. We criticize some traditional analysis considering that a prepositional phrase may fill the subject function; and stressed on the fact the impersonal construction is not necessarily translated by an impersonal construction in another language. Further studies may discuss several issues: the representation of this kind of pronoun in other multi-stratal dependency frameworks, its representation within a monostratal framework, and its frequency in ProDrop languages. It will also be interesting to study thoroughly government patterns and semantic classification of verbs heading nomeaning zero-phonetic subject pronouns in Arabic.

\section{Acknowledgments}

I would like to express my gratitude for Igor Mel'čuk and Yasmina Milicevic for accepting reading and commenting this work from its early phase.

\section{References}

Ahmed Kamal El-Din Abdel-Hamid. 1972. A transfer grammar of English and Arabic. $\mathrm{PhD}$ dissertation. University of Texas, Austin.

Abdelkader Fassi Fehri. 1982. Linguistique arabe: forme et interprétation. Press of the faculty of Letters and Human Sciences of Mohammed V University, Rabat.

Wolfdietrich Fischer. 2002. A Grammar of Classical Arabic. Translated from the German by Jonathan Rodgers. Yale University Press, New Haven and London, UK.

David Teeple. 2008. The Arabic Impersonal Passive in OT. University of California, Santa Cruz.

Dina El Kassas. 2005. Etude contrastive $d u$ Français et de l'Arabe dans une perspective de génération multilingue. $\mathrm{PhD}$ dissertation, Paris VII University, Paris.

Matthew S. Dryer. 2008. Expression of Pronominal Subjects. The World Atlas of Language Structures Online, ed. Haspelmath, Martin, Matthew S. Dryer, David Gil, and Bernard Comrie, chp. 101. Max Planck Digital Library, Munich. http://wals.info/feature/101. (Accessed on 2011-03-28.)

Abd-Alkareem Massalha. 2005. The Agentive Passive Construction in English and Its Translation into Arabic. M.A. dissertation, University of Haifa, Haifa.

Igor Mel'čuk. 1988. Dependency Syntax: Theory and Practice. The SUNY Press, Albany, N.Y.

Igor Mel'čuk. 2006. Aspects of the Theory of Morphology. Ed. de Gruyter, Berlin - New York.

A. Mohammad Mohammad. 1999. Word Order and Pronominalization in Palestinian Arabic. Current Issues in Linguistic Theory. John Benjamins, Amsterdam / Philadelphia.

George Nehmeh Saad. 1982. Transitivity, causation and passivization: A semantic-syntactic study of the verb in Classical Arabic. Kegan Paul International ed. London. 